Author Index to Volume 33 - 2006

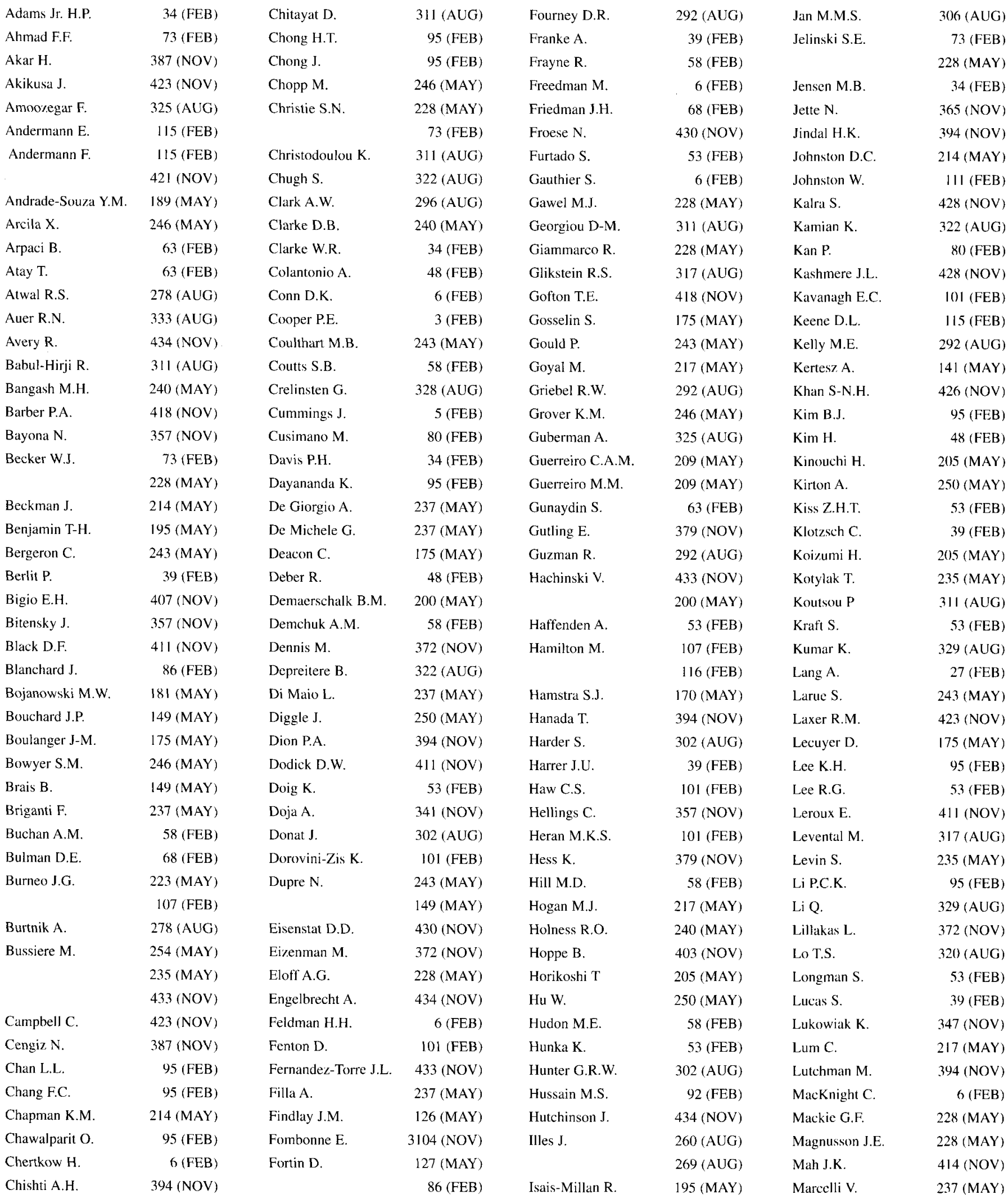




\section{Author Index to Volume 33 - 2006}

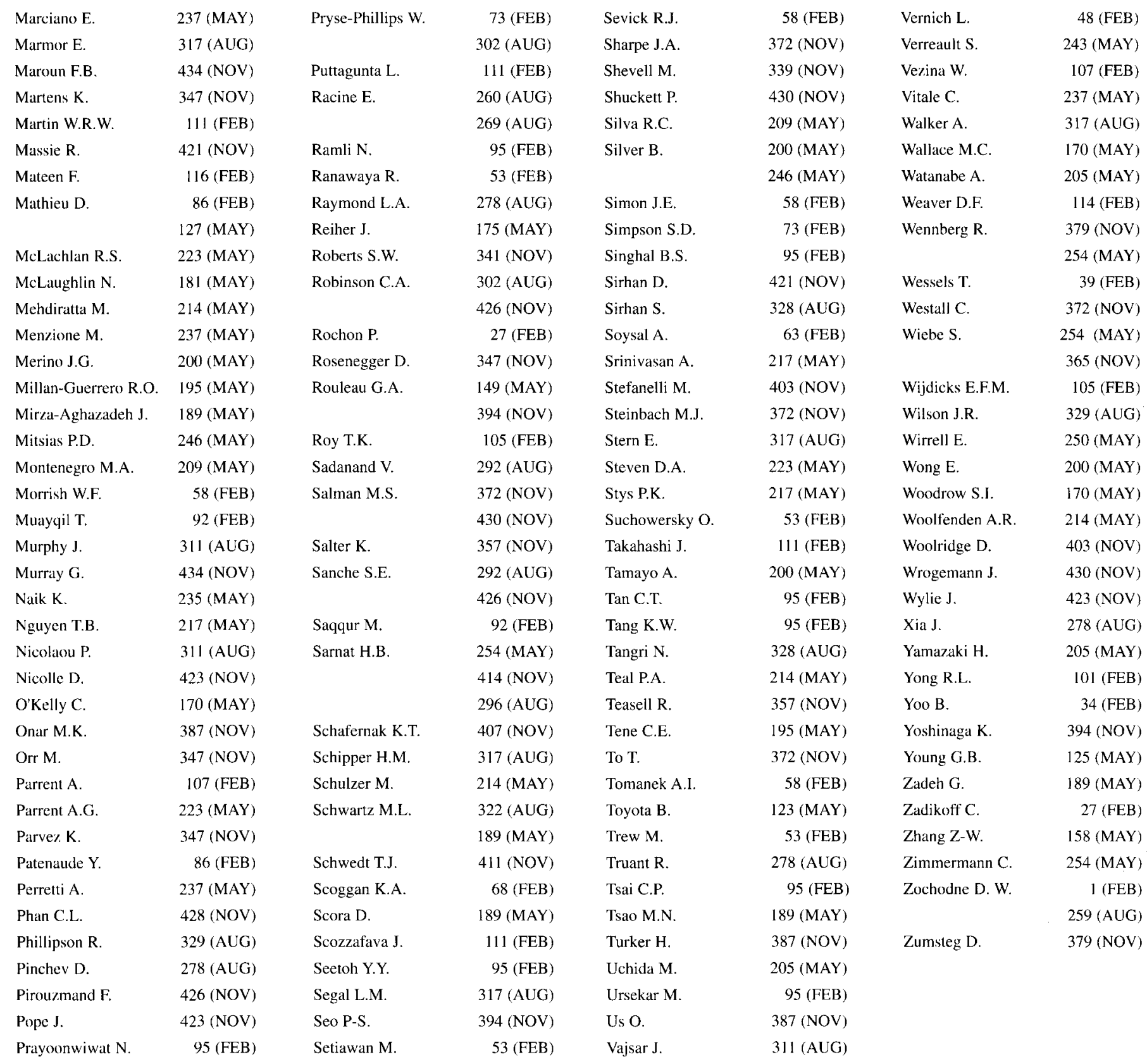




\section{Subject Index to Volume 33 - 2006}

ABSCESS

Altered Mental Status and Retro-auricular Mass

317 (AUG)

N. Paucivorans Infection Presenting as a Brain Abscess

426 (NOV)

\section{ALZHEIMER'S}

Alzheimer's Disease Clinical Trials: Where Are We Now?

Canadian Guidelines for the Development of Antidementia Therapies: A Conceptual Summary

\section{ANEURYSMS}

Delayed Diagnosis of Ruptured Aneurysms When Vasospasm is Present: Is Immediate Surgery Best?

Aneurysmal Surgery in the Presence of Angiographic Vasospasm: An Outcome Assessment 181 (MAY)

ANGIOPLASTY

Acute Anterior Circulation Stroke: Recanalization Using Clot Angioplasty 217 (MAY)

\section{ARTERIOVENOUS MALFORMATIONS}

Radiosurgical Retreatment for Brain Arteriovenous Malformation

\section{ASTROCYTOMAS}

The Role of Chemotherapy in the Treatmen of Malignant Astrocytomas $127(\mathrm{MAY})$

ATAXIA

CACNA1A Mutation in a EA-2 Patient Responsive to Acetazolamide and Valproic Acid

Herediatry Ataxia, Spastic Paraparesis and Neuropathy in the French-Canadian Population 149 (MAY)

AUTISM

Autisum and MMR Vaccination or Thimerosal Exposure: An Urban Legend? $\quad 339$ (NOV) Immunizations and Autism: A Review of the Literature

341 (NOV)

\section{BEHCET'S DISEASE}

Effects of High Stimulus Frequencies on SEPs of Patients with Neuro-Behcet's Disease $387(\mathrm{NOV})$

BIPAP

BiPAP in Early Guillain-Barre Syndrome May Fail 105 (FEB)

\section{BRAIN INJURY}

Discharge Destination from Acute Care after Traumatic Brain Injury

\section{BRAIN TUMOURS}

Midline Cerebellar Medulloblastoma in a Seventy-One Year-Old Patient

MR-Pathological Comparison in F98-Fischer Glioma Model Using a Human Gantry 86 (FEB)

The Role of Chemotherapy in the Treatment of Malignant Astrocytomas 127 (MAY)

Pituitary Carcinoma with Subependymal Spread
Chronic Cluster-like Headache Secondary to an Epidermoid Clival Lesion $421(\mathrm{NOV})$

\section{CARDIAC COMPLICATION}

Valvular Heart Disease in Pergolide-Treated Parkinson's Disease

Cardiac Valvulopathy Associated with Pergolide Use

\section{CARDIOLOGY}

Stroke Recurrence and its Prevention in Patients with Patent Foramen Ovale

39 (FEB)

\section{CAVERNOUS HEMANGIOMA}

Claude Syndrome 'Plus' in an Adolescent 430 (NOV)

\section{CEREBROVASCULAR DISEASE}

Blood Pressure as an Independent Prognostic Factor in Acute Ischemic Stroke 34 (FEB) Stroke Recurrence and its Prevention in Patients with Patent Foramen Ovale 39 (FEB)

MR Angiography Compared to Conventiona Selective Angiography in Acute Stroke 58 (FEB) ASPECT Scoring to Estimate $>1 / 3$ Middle Cerebral Artery Territory Infarction 200 (MAY) Reduction in IV t-PA Door to Needle Times Using an Acute Stroke Triage Pathway 214 (MAY) Acute Anterior Circulation Stroke: Recanalization Using Clot Angioplasty 217 (MAY) Recovery in a Patient with Locked-In Syndrome 246 (MAY)

A Pediatric Case of Reversible Segmental Cerebral Vasoconstriction 250 (MAY) Anterior Spinal Artery Infarction at the Cervicomedullary Junction

Stroke Training in Canadian Neurology Residency Training Programs

433 (NOV)

\section{CHIARI}

Saccadic Adaptation in Chiari Type II Malformation

CHOLESTEATOMA

Altered Mental Status and Retro-auricular Mass

317 (AUG)

\section{CLINICAL TRIALS}

Na-Methyl Histamine Safety and Efficacy in Migraine Prophylaxis: Phase III Study 195 (MAY) Clobazam as Add-On Therapy in Children with Epileptic Encephalopathy 209 (MAY) Randomized Trials and Collaborative Research in Epilepsy Surgery: Future Directions 365 (NOV)

CMT

A Novel GDAP1 Mutation 439delA is Associated with Autosomal Recessive CMT Disease 311 (AUG)

COMPUTED TOMOGRAPHY

ASPECT Scoring to Estimate $>1 / 3$ Middle Cerebral Artery Territory Infarction

200 (MAY)

\section{CREUTZFELDT-JAKOB DISEASE}

A Case of Familial Creutzfeldt-Jakob Disease Presenting with Dry Cough 243 (MAY)

\section{DEEP BRAIN STIMULATION}

Referrals for Movement Disorder Surgery: Under-representation of Females and Reasons for Refusal
DEGENERATIVE DISEASES

Canadian Guidelines for the Development of Antidementia Therapies: A Conceptual Summary

A Case of Familial Creutzfeldt-Jakob Disease Presenting with Dry Cough 243 (MAY)

\section{DEMENTIA}

Canadian Guidelines for the Development of Antidementia Therapies: A Conceptual Summary

Progess in Clinical Neurosciences: Frontotemporal Dementia-Pick's Disease

Bilateral Agenesis of the Hippocampal Dentate Gyrus in a Neurologically Normal Adult

\section{DEVELOPMENTAL NEUROBIOLOGY}

Postnatal Development of the Mammalian Neocortex: Role of Activity Revisited 158 (MAY)

\section{DEVELOPMENTAL NEUROLOGY}

Postnatal Development of the Mammaljan Neocortex: Role of Activity Revisited 158 (MAY)

\section{EDITORIAL}

Lost Fundamentals in Neurosciences - A Call for Discussion I (FEB)

The Optimal Use of Triptans - Sooner is Better

Alzheimer's Disease Clinical Trials: Where Are We Now?

Canadian Neurosurgical Manpower: Need

for Self-Determination

Those Troublesome but Never Tiresome Triphasic Waves

$123(\mathrm{MAY})$

layed Diagnosis of Ruptured Aneurysm. When Vasospasm is Present: Is Immediate Surgery Best? hanges and Leader

Autisum and MMR Vaccination or Thimerosa Exposure: An Urban Legend? 339 (NOV)

\section{EDUCATION}

Canadian Neurosurgical Manpower: Need for Self-Determination $123(\mathrm{MAY})$

Unemployment in an Underserviced Specialty? The Need for Co-ordinated Workforce Planning in Canadian Neurosurgery $170(\mathrm{MAY})$

Neuroembryology in Paediatric Neurology Training Programmes

254 (MAY)

Responsabilites Neuroethiques 260 (AUG)

Neuroethical Responsibilitie 269 (AUG)

Letter to Fditor - Re: Lost Fundamentals in Neurosciences 333 (AUG)

\section{EEG DYNAMICS}

Those Troublesome but Never Tiresome Triphasic Waves

$125(\mathrm{MAY})$

Triphasic Waves versus Nonconvulsive Status Epilepticus: EEG Distinction Triphasic Waves and Nonconvulsive Status Epilepticus

17.5 (MAY)

433 (NOV)

ELECTROENCEPHALOGRAPHY

Those Troublesome but Never Tiresome Triphasic Waves

Triphasic Waves versus Nonconvulsive Status Epilepticus: EEG Distinction 
Triphasic Waves and Nonconvulsive Status Epilepticus

433 (NOV)

\section{ENCEPHALITIS}

Utility of lctal Spect in the Presurgical Evaluation of Rasmussen's Encephalitis 107 (FEB) Rasmussen's Encephalitis in a 58-Year-Old Female: Still a Variant? $302(\mathrm{AUG})$

West Nile Virus Encephalomyelitis with Polio-like Paralysis \& Nigral

Degeneration

407 (NOV)

\section{ENCEPHALOMYELITIS}

West Nile Virus Encephalomyelitis with Polio-like Paralysis \& Nigral

Degeneration

407 (NOV)

\section{ENCEPHALOPATHY}

Susac Syndrome with Frontal Intermitten Rhythmic Delta Activity (FIRDA) 403 (NOV)

\section{EPILEPSY}

Triphasic Waves versus Nonconvulsive Status Epilepticus: EEG Distinction 175 (MAY)

Clobazam as Add-On Therapy in Children with Epileptic Encephalopathy 209 (MAY)

Morbidity Associated With the use of Intracranial Electrodes for Epilepsy Surgery

223 (MAY)

Rasmussen's Encephalitis in a 58-Year-Old Female: Still a Variant?

Intractable Childhood Epilepsy and Maternal Fatigue

306 (AUG)

Randomized Trials and Collaborative Rewearch in Epilepsy Surgery: Future Directions

$365(\mathrm{NOV})$

Triphasic Waves and Nonconvulsive Status Epilepticus

433 (NOV)

\section{EPILEPSY - PEDIATRIC}

Clobazam as Add-On Therapy in Children with Epileptic Encephalopathy 209 (MAY

Intractable Childhood Epilepsy and Maternal Fatigue

306 (AUG)

\section{EPILEPSY PHARMACOLOGY}

Clobazam as Add-On Therapy in Children with Epileptic Encephalopath

209 (MAY)

\section{EPILEPSY SURGERY}

Morbidity Associated With the use of Intracranial Electrodes for Epilepsy Surgery 223 (MAY)

Randomized Trials and Collaborative Research in Epilepsy Surgery: Future Directions

$365(\mathrm{NOV})$

\section{ETHICS}

Responsabilites Neuroethiques

Neuroethical Responsibilities

260 (AUG) 269 (AUG)

\section{EVIDENCE BASED MEDICINE}

Progress: Measuring the Benefit

254 (MAY)

\section{EVOKED POTENTIALS}

Cervico-Oculo-Acoustic Syndrome in a Male with Consanguineous Parents

EXCHANGE ARTICLE

Magnetic Resonance Imaging of Asians with Multiple Sclerosis was Similar to that of the West

\section{EXPERIMENTAL NEUROSCIENCES}

Learning at a Snail's Pace

347 (NOV)

\section{EYE MOVEMENTS}

Saccadic Adaptation in Chiari Type II

$$
\text { Malformation }
$$

Convergence Paralysis as a Manifestation of Polyarteritis Nodosa

Claude Syndrome 'Plus' in an Adolescent 430 (NOV)

\section{FIBROUS DYSPLASIA}

Fibrous Dysplasia of the Skull Base Presenting Acutely in an Adult

\section{FIRDA}

Susac Syndrome with Frontal Intermittent Rhythmic Delta Activity (FIRDA) 403 (NOV)

\section{FRONTAL LOBE DEMENTIA}

Progess in Clinical Neurosciences: Frontotemporal Dementia-Pick's Disease

141 (MAY)

\section{GENETICS}

A Novel GDAP1 Mutation 439delA is Associated with Autosomal Recessive CMT Disease

311 (AUG)

GENETICS - CLINICAL and Neuropathy in the French-Canadian Population 149 (MAY)

Cervico-Oculo-Acoustic Syndrome in a Male with Consanguineous Parents 237 (MAY)

A Novel GDAP1 Mutation 439delA is

Associated with Autosomal Recessive CMT Disease

311 (AUG)

\section{GLIOMA}

MR-Pathological Comparison in F98-Fischer Glioma Model Using a Human Gantry 86 (FEB)

\section{GUILLAIN BARRÉ}

BiPAP in Early Guillain-Barre Syndrome May Fail

105 (FEB)

HEAD TRAUMA

Whiplash and Concussion: Similar Acute Changes in Middle-Latency SEPs 379 (NOV)

\section{HEADACHE}

Pain Free Efficacy of Sumatriptan in the Early Treatment of Migraine

$73(\mathrm{FEB})$

Subdural Effusions in the Posterior Fossa Associated with Spontaneous Intracranial Hypotension 205 (MAY)

Demographics and Clinical Features of Patients Referred to Headache Specialists 228 (MAY) Fibrous Dysplasia of the Skull Base Presenting Acutely in an Adult

Intractable SUNCT Cured After Resection of a Pituitary Microadenoma 41] (NOV)

Chronic Cluster-like Headache Secondary to an Epidermoid Clival Lesion

421 (NOV)

\section{HEALTH SERVICES RESEARCH}

Demographics and Clinical Features of Patients Referred to Headache Specialists 228 (MAY)

\section{HIPPOCAMPUS}

Bilateral Agenesis of the Hippocampal Dentate Gyrus in a Neurologically Normal Adult
Herediatry Ataxia, Spastic Paraparesis
HUNTING'TON'S DISEASE

Polyglutamine Expansion Neurodegenerative Diseases

\section{HYPERTENSION}

Blood Pressure as an Independent Prognostic Factor in Acute Ischemic Stroke $\quad 34$ (FEB)

HYPOGLOSSAL NERVE.

Unilateral Hypoglossal Nerve Palsy Following the Use of the Laryngeal Mask Airway 320 (AUG) Hypoglossal Nerve Injury 322 (AUG)

\section{IMMUNIZATION}

Autisum and MMR Vaccination or Thimerosal Exposure: An Urban Legend? 339 (NOV)

Immunizations and Autism: A Review of the Literature $341(\mathrm{NOV})$

INFECTIONS OF THE NERVOUS SYSTEM

Propionibacterium Acnes Infections after Cranial Neurosurgery 292 (AUG)

Altered Mental Status and Retro-auricular Mass 317 (AUG)

N. Paucivorans Infection Presenting as a Brain Abscess $426(\mathrm{NOV})$

Re: Propionibacterium Acnes Infections after Cranial Neurosurgery

434 (NOV)

\section{INTERVENTIONAL NEURORADIOLOGY}

Acute Anterior Circulation Stroke: Recanalization Using Clot Angioplasty 217 (MAY)

\section{INTRACRANIAL HYPOTENSION}

Subdural Effusions in the Posterior Fossa Associated with Spontaneous Intracranial Hypotension

205 (MAY)

KENNEDY'S DISEASE

Polyglutamine Expansion Neurodegenerative Diseases

LEUKODYSTROPHY

Optic Nerve Enlargement Associated with Globoid Cell Leukodystrophy 235 (MAY)

MACHADO-JOSEPH DISEASE

Polyglutamine Expansion Neurodegenerative Diseases 278 (AUG)

MAGNETIC RESONANCE IMAGING

MR Angiography Compared to Conventional Selective Angiography in Acute Stroke 58 (FEB) MR-Pathological Comparison in F98-Fischer Glioma Model Using a Human Gantry 86 (FEB) Magnetic Resonance Imaging of Asians with West- EXCHANGE ARTICLE Brain \& Chiasmal Herniations into Sella after Medical Treatment of Prolactinoma 240 (MAY)

\section{MEDULLOBLASTOMA}

Midline Cerebellar Medulloblastoma in a Seventy-One Year-Old Patient 101 (FEB)

\section{MEMORIAM}

Obituary:

Nico M. van Gelder (1933-2005)

114 (FEB)

In Memoriam - Katherine Metrakos July 13,1924- May 12,2005
Occipital Condyle Fracture with Associated Multiple Sclerosis was Similar to that of the 
MEMORY

Learning at a Snail's Pace

$347(\mathrm{NOV})$

MIGRAINE

Motor and Occipital Cortex Excitability in Migraine Patients

Pain Free Efficacy of Sumatriptan in the Early Treatment of Migraine

Na-Methyl Histamine Safety and Efficacy in Migraine Prophylaxis: Phase III Study 195 (MAY) Demographics and Clinical Features of Patients Referred to Headache Specialists 228 (MAY)

\section{MIGRAINE RESEARCH}

Motor and Occipital Cortex Excitability in Migraine Patients

$63(\mathrm{FEB})$

Pain Free Efficacy of Sumatriptan in the Early Treatment of Migraine

Na-Methyl Histamine Safety and Efficacy in

Migraine Prophylaxis: Phase III Study 195 (MAY)

MOLECULAR GENETICS

CACNA IA Mutation in a EA-2 Patient Responsive to Acetazolamide and Valproic Acid 68 (FEB)

\section{MOTOR CORTEX}

Motor and Occipital Cortex Excitability in Migraine Patients

\section{MOTOR EVOKED POTENTIAL}

Motor and Occipital Cortex Excitability in Migraine Patients

63 (FEB)

\section{MOVEMENT DISORDER SURGERY}

Referrals for Movement Disorder Surgery: Under-representation of Females and Reasons for Refusal

MOVEMENT DISORDERS

Valvular Heart Disease in Pergolide-Treated Parkinson's Disease

Cardiac Valvulopathy Associated with Pergolide Use

Referrals for Movement Disorder Surgery: Under-representation of Females and Reasons for Refusa

MULTIPLE SCLEROSIS

Magnetic Resonance Imaging of Asians with Multiple Sclerosis was Similar to that of the West - EXCHANGE ARTICLE 95 (FEB)

MULTIPLE SCLEROSIS MRI

Magnetic Resonance Imaging of Asians with Multiple Sclerosis was Similar to that of the West - EXCHANGE ARTICLE 95 (FEB)

\section{NERVE INJURY}

Unilateral Hypoglossal Nerve Palsy Following the Use of the Laryngeal Mask Airway 320 (AUG) Occipital Condyle Fracture with Associated 322 (AUG)

\section{NEURO-ONCOLOGY}

Midline Cerebellar Medulloblastoma in Seventy-One Year-Old Patient

The Role of Chemotherapy in the Treatment of Malignant Astrocytomas 127 (MAY)

\section{NEURO-OPHTHAMOLOGY}

Cervico-Oculo-Acoustic Syndrome in a Male with Consanguineous Parents

\section{NEURODEGENERATIVE DISORDERS}

Polyglutamine Expansion Neurodegenerative Diseases $278(\mathrm{AUG})$

\section{NEUROETHICS}

Responsabilites Neuroethiques 260 (AUG) Neuroethical Responsibilities 269 (AUG)

NEUROFIBROMA

Sepsis from Neurofibromatosis $\quad 328$ (AUG)

Purification of the NF2 Tumor Suppressor Protein from Human Erythrocytes 394 (NOV)

\section{NEUROFIBROMATOSIS}

Sepsis from Neurofibromatosis

Purification of the NF2 Tumor Suppressor Protein from Human Erythrocytes 394 (NOV)

\section{NEUROGENETICS}

CACNAlA Mutation in a EA-2 Patient Responsive to Acetazolamide and Valproic Acid 68 (FEB Purification of the NF2 Tumor Suppressor Protein from Human Erythrocytes 394 (NOV)

\section{NEUROIMAGING}

A Patient with Neurosarcoidosis 92 (FEB)

Optic Nerve Enlargement Associated with Globoid Cell Leukodystrophy

Anterior Spinal Artery Infarction at the Cervicomedullary Junction

235 (MAY)

$418(\mathrm{NOV})$

\section{NEUROLOGY - EDUCATION}

To the Editor - In Regards to CCNS

116 (FEB)

NEUROLOGY - PAEDIATRIC

Optic Nerve Enlargement Associated with Globoid Cell Leukodystrophy 235 (MAY)

A Pediatric Case of Reversible Segmental Cerebral Vasoconstriction 250 (MAY)

Intractable Childhood Epilepsy and Maternal Fatigue

$306(\mathrm{AUG})$

A 10-Year-Old Girl with Progressive Generalized Weakness

414 (NOV)

NEUROPATHOLOGICAL CONFERENCE

A 10-Year-Old Girl with Progressive Generalized Weakness

414 (NOV)

\section{NEUROPATHOLOGY}

Bilateral Agenesis of the Hippocampal Dentate Gyrus in a Neurologically Normal Adult 296 (AUG)

A 10-Year-Old Girl with Progressive Generalized Weakness

$414(\mathrm{NOV})$

NEUROPATHY

Herediatry Ataxia, Spastic Paraparesis and Neuropathy in the French-Canadian 149 (MAY) Population

A Novel GDAP1 Mutation 439delA is Associated with Autosomal Recessive CMT Disease

Unilateral Hypoglossal Nerve Palsy Following the Use of the Laryngeal Mask Airway 320 (AUG)

Occipital Condyle Fracture with Associated $322(\mathrm{AUG})$

Unilateral Atrophy of Fungiform Papillae Associated with Lingual Nerve Injury 428 (NOV)

\section{NEUROPATHY - PERIPHERAL}

A Novel GDAPl Mutation 439delA is Associated with Autosomal Recessive CMT Disease
A 10-Year-Old Girl with Progressive Generalized Weakness

414 (NOV)

\section{NEURORADIOLOGY}

A Patient with Neurosarcoidosis

92 (FEB)

NEUROSARCOIDOSIS

A Patient with Neurosarcoidosis

92 (FEB)

\section{NEUROSCIENCES}

Postnatal Development of the Mammalian Neocortex: Role of Activity Revisited 158 (MAY) Letter to Editor - Re: Lost Fundamentals in Neurosciences

Learning at a Snail's Pace 347 (NOV)

\section{NEUROSURGERY}

Propionibacterium Acnes Infections after Cranial Neurosurgery

Re: Propionibacterium Acnes Infections after Cranial Neurosurgery

\section{NEUROSURGICAL PRACTICE}

Canadian Neurosurgical Manpower: Need for Self-Determination

Unemployment in an Underserviced Specialty" The Need for Co-ordinated Workforce Planning in Canadian Neurosurgery

Propionibacterium Acnes Infections after Cranial Neurosurgery

Re: Propionibacterium Acnes Infections after Cranial Neurosurgery $434(\mathrm{NOV})$

\section{NEUROVIROLOGY}

West Nile Virus Encephalomyelitis with Polio-like Paralysis \& Nigral Degeneration

$407(\mathrm{NOV})$

\section{OUTCOMES RESEARCH}

Discharge Destination from Acute Care after Traumatic Brain Injury

48 (FEB)

\section{PARKINSON'S DISEASE}

Valvular Heart Disease in Pergolide-Treated Parkinson's Disease

111 (FEB)

Cardiac Valvulopathy Associated with Pergolide Use

Referrals for Movement Disorder Surgery: Under-representation of Females and Reasons for Refusal

\section{PARKINSONISM}

West Nile Virus Encephalomyelitis with Polio-like Paralysis \& Nigral

Degeneration

$407(\mathrm{NOV})$

\section{PERIPHERAL NERVE}

Unilateral Hypoglossal Nerve Palsy Following the Use of the Laryngeal Mask Airway 320 (AUG)

\section{PICK'S DISEASE}

Progess in Clinical Neurosciences: Frontotemporal Dementia-Pick's Disease

14I (MAY)

\section{PITUITARY}

Brain \& Chiasmal Herniations into Sella after Medical Treatment of Prolactinoma 240 (MAY)

Pituitary Carcinoma with Subependymal Spread

Intractable SUNCT Cured After Resection of a Pituitary Microadenoma

$411(\mathrm{NOV})$ 


\section{PITUITARY ADENOMAS}

Validation of a Quality-of-Life Questionnaire for Patients with Pituitary Adenoma 80 (FEB)

Brain \& Chiasmal Herniations into Sella after Medical Treatment of Prolactinoma $240(\mathrm{MAY})$

Intractable SUNCT Cured After Resection of a Pituitary Microadenoma 411 (NOV)

\section{PITUITARY TUMOUR}

Validation of a Quality-of-Life Questionnaire for Patients with Pituitary Adenoma

80 (FEB)

Brain \& Chiasmal Herniations into Sella after Medical Treatment of Prolactinoma

Pituitary Carcinoma with Subependymal Spread

\section{POLYNEUROPATHY}

A 10-Year-Old Girl with Progressive Generalized Weakness

PRION

A Case of Familial Creutzfeldt-Jakob Disease Presenting with Dry Cough 243 (MAY)

PTOSIS

Fibrous Dysplasia of the Skull Base Presenting Acutely in an Adult

\section{QUALITY OF LIFE}

Validation of a Quality-of-Life Questionnaire for Patients with Pituitary Adenoma

$80($ FEB $)$

\section{RADIATION}

Radiosurgical Retreatment for Brain Arteriovenous Malformation

\section{RADIOSURGERY}

Radiosurgical Retreatment for Brain 189 (MAY)

RASMUSSEN'S SYNDROME

Utility of Ictal Spect in the Presurgical Evaluation of Rasmussen's Encephalitis

Rasmussen's Encephalitis in a 58-Year-Old Female: Still a Variant?

\section{REHABILITATION}

Stroke Recovery and Rehabilitation $\quad 357$ (NOV)

\section{RESIDENCY TRAINING}

Canadian Neurosurgical Manpower: Need for Self-Determination 123 (MAY)

Unemployment in an Underserviced Specialty? The Need for Co-ordinated Workforce Planning in Cunadian Neurosurgery 170 (MAY) Neuroembryology in Paediatric Neurology Training Programmes 254 (MAY)

\section{RESPIRATORY}

BiPAP in Early Guillain-Barre Syndrome May Fail

105 (FEB)

SARCOIDOSIS

A Patient with Neurosarcoidosis

92 (FEB)

\section{SEIZURES}

Morbidity Associated With the use of Intracranial Electrodes for Epilepsy Surgery 223 (MAY) Rasmussen's Encephalitis in a 58-Year-Old Female: Still a Variant?
SKULL BASE

Saccadic Adaptation in Chiari Type II Malformation

372 (NOV)

SOMATOSENSORY EVOKED POTENTIAL

Whiplash and Concussion: Similar Acute Changes in Middle-Latency SEPs 379 (NOV)

Effects of High Stimulus Frequencies on SEPs of Patients with Neuro-Behcet's Disease 387 (NOV)

SPECT

Utility of Ictal Spect in the Presurgical Evaluation of Rasmussen's Encephalitis 107 (FEB)

STROKE

Blood Pressure as an Independent Prognostic Factor in Acute Ischemic Stroke 34 (FEB)

Stroke Recurrence and its Prevention in Patients with Patent Foramen Ovale 39 (FEB)

MR Angiography Compared to Conventional Selective Angiography in Acute Stroke 58 (FEB) ASPECT Scoring to Estimate $>1 / 3$ Middle Cerebral Artery Territory Infarction 200 (MAY) Reduction in IV t-PA Door to Needle Times Using an Acute Stroke Triage Pathway 214 (MAY) Recovery in a Patient with Locked-In Syndrome

246 (MAY)

Stroke Recovery and Rehabilitation

Anterior Spinal Artery Infarction at the Cervicomedullary Junction 357 (NOV)

oke Training in Canadian Neurology Residency Training Programs

433 (NOV)

\section{STROKE REHABILITATION}

Recovery in a Patient with Locked-In Syndrome

246 (MAY)

Stroke Recovery and Rehabilitation

357 (NOV)

\section{SUBARACHNOID HEMORRHAGE}

Delayed Diagnosis of Ruptured Aneurysm When Vasospasm is Present: Is Immediate Surgery Best?

Aneurysmal Surgery in the Presence of Angiographic Vasospasm: An Outcome Assessment 181 (MAY)

\section{SUBDURAL HEMATOMA}

Subdural Effusions in the Posterior Foss Associated with Spontaneous Intracranial Hypotension

205 (MAY)

\section{SUNCT}

Intractable SUNCT Cured After Resection of a Pituitary Microadenoma 411 (NOV)

\section{SUSAC SYNDROME}

Susac Syndrome with Frontal Intermittent Rhythmic Delta Activity (FIRDA) 403 (NOV)

\section{THERAPEUTICS}

Canadian Guidelines for the Development of Antidementia Therapies: A Conceptual Sumnary $6(\mathrm{FEB})$

\section{THROMBOLYSIS}

Stroke Training in Canadian Neurology Residency Training Programs 433 (NOV)

\section{TISSUE PLASMINOGEN ACTIVATOR}

Stroke Training in Canadian Neurology Residency Training Programs
TONGUE

Unilateral Atrophy of Fungiform Papillae Associated with Lingual Nerve Injury 428 (NOV)

TP

Reduction in IV t-PA Door to Needle Times Using an Acute Stroke Triage Pathway 214 (MAY)

\section{TRAUMA}

Discharge Destination from Acute Care after Traumatic Brain Injury

Whiplash and Concussion: Similar Acute Changes in Middle-Latency SEPs 379 (NOV)

\section{TRIPTANS}

The Optimal Use of Triptans - Sooner is Better

TUMOURS

Altered Mental Status and Retro-auricular Mass

VASCULITIS

Convergence Paralysis as a Manifestation of Polyarteritis Nodosa 423 (NOV)

\section{VASOSPASM}

Delayed Diagnosis of Ruptured Aneurysms When Vasospasm is Present: Is Immediate Surgery Best?

Aneurysmal Surgery in the Presence of Angiographic Vasospasm: An Outcome Assessment

A Pediatric Case of Reversible Segmental Cerebral Vasoconstriction 250 (MAY)

\section{VON RECKLINGHAUSEN'S}

Sepsis from Neurofibromatosis

328 (AUG)

WEST NILE VIRUS

West Nile Virus Encephalomyelitis with Polio-like Paralysis \& Nigral

Degeneration 407 (NOV)

\section{WHIPLASH}

Whiplash and Concussion: Similar Acute Changes in Middle-Latency SEPs 